\title{
Study on a stepped eco-filter for treating greywater from single farm household
}

\author{
Jianjun Chen ${ }^{1}$ Zaiyi Liao ${ }^{1}$ Shaoyong $\mathrm{Lu}^{2} \cdot$ Guangcai Hu$^{1} \cdot$ Yaoxin $\mathrm{Liu}^{3}$ • \\ Cilai Tang ${ }^{1}$
}

Received: 4 November 2016/ Accepted: 23 January 2017/Published online: 9 February 2017

(c) The Author(s) 2017. This article is published with open access at Springerlink.com

\begin{abstract}
A stepped eco-filter based greywater treating facility was built on-site in a typical farm house of China. This study was aimed to investigate the hydraulic loading rate (HLR) for the optimal removal efficiency and to analyze the processing performance throughout an entire year. The results showed that, the average value of TP from the influent was much lower while the linear alkylbenzene sulfonate was a little higher compared with other related studies. The removal rates of the indexes were all showed a distinct decline and dropped to a low level while the HLR was raised from $0.2 \mathrm{~m}^{3} /\left(\mathrm{m}^{2}\right.$ day $)$ to $0.4 \mathrm{~m}^{3} /\left(\mathrm{m}^{2}\right.$ day $)$. Therefore, the optimal HLR of the process ought to be in the range of $0.2-0.4 \mathrm{~m}^{3} /\left(\mathrm{m}^{2}\right.$ day $)$. The average system removal rates in summer were all higher than that in winter, but the facility still performed well in winter. Clogging has never occurred in the facility during the operation over an entire year. Together with the good performance, advantaged of lower cost and easier maintenance, this process has shown good applicability for greywater treatment in rural area.
\end{abstract}

Keywords Greywater · Eco-filter · Farm household · Hydraulic loading rate $\cdot$ Linear alkylbenzene sulfonate

Jianjun Chen

jjchen1980s@hotmail.com

1 College of Hydraulic and Environment Engineering, China Three Gorges University, Yichang 443002, China

2 State Key Laboratory of Environmental Criteria and Risk Assessment, Chinese Research Academy of Environmental Sciences, Beijing 100012, China

3 College of Environmental Science and Engineering, Fujian Key Laboratory of Pollution Control and Resource Reuse, Fujian Normal University, Fuzhou 350007, Fujian, China

\section{Introduction}

Pollutions resulting from the domestic liquid waste have largely increased in current China due to the intensified use of chemical products driven by the rapid economic development. The large amount of untreated domestic sewage caused serious degradation of the natural water quality and led to serious environmental damage (Wang et al. 2011); thus, it is urgent to develop suitable technologies for treating domestic wastewater in China's rural regions. The rural domestic sewages can be segregated into greywater (GW) and black-water (BW), the GW is generated from washing basin, bathroom, kitchen, laundry and black-water is mainly from toilet and farm life stock (Halalsheh et al. 2008). Our previous field survey showed that BW generated from the most peasant households has been already collected by septic tanks and reused for fertilization in the region, but the GW was normally discharged directly into the drainage ditch and then flowed into the streams. Therefore, this study is aimed to investigate the process for the treatment of rural GW and to build a practical system on-site.

In comparison with the traditional centralized urban wastewater treatment, the decentralized process is likely to be low in both operating and initial cost because no large sewage pipe system is needed. Currently, the decentralized techniques adopted for GW treatment can be categorized into three groups: physical, chemical, and biological systems. Physical methods include sand and membrane filtration, and the chemical methods include coagulation and ion exchange (Marc et al. 2007; Huelgas and Funamizu 2009). The biological system mainly include membrane bioreactors (MBR), anaerobic sludge blanket (UASB), constructed wetland $(\mathrm{CW})$, and vermifiltration $(\mathrm{VF})(\mathrm{Li}$ et al. 2009; Wang et al. 2010). When treating the GW from 
households, more and more studies focus on the bio-ecological technology due to the potentially low cost, high efficiency and easy maintenance desired by potential users. A recycled vertical flow constructed wetland showed an overall removal rate of $81 \%$ for COD and $70 \%$ for TN and $\mathrm{TP}$, and the treated GW sufficiently to meet current standards for unlimited irrigation except for the complete removal of Fecal coliforms (Gross et al. 2007). An comparative study showed that shallow beds led to higher $\mathrm{BOD}_{5}$ and COD removals, wherever the presence of plants in the vertical flow constructed wetland (VFCW) caused higher removal rate of the linear alkylbenzene sulfonate (LAS) (Kadewa et al. 2010). A low cost and simple slanted soil system has been reported to perform high removal rate in both PCOD (94-97\%) and BDOC (88-89\%), whilst the LAS removal rates were more than $90 \%$ and final concentrations $(2.3-3.3 \mathrm{mg} / \mathrm{L}$ ) were sufficiently lower than the level for irrigation use (Ushijima et al. 2013). Adugna et al. (2014) reported that the vermifilter was better than the filter without earthworms in removing $\mathrm{BOD}_{5}, \mathrm{COD}$, TSS and coliforms, and higher removal rates were achieved with the HLR of $0.064 \mathrm{~m}^{3} /\left(\mathrm{m}^{2}\right.$ day) compare to $0.19 \mathrm{~m}^{3} /\left(\mathrm{m}^{2}\right.$ day $)$ in all parameters.

In recent years, more and more research focus on the characteristics of domestic GW and the GW treatment process (Ghaitidak and Yadav 2013; Jabornig 2014; Edwin et al. 2014). However, many of the stimulated tests were carried out in the lab for a relatively short period of time. The correlative changes between the pollutants removal efficiency and the process parameters, such as the hydraulic loading rate (HLR) have been rarely interpreted. In addition, our field survey showed that the trenching process such as the conventional $\mathrm{CW}$ was out of the question because of a thin soil cover $(15-25 \mathrm{~cm})$ on the ground around the farm house. In light of what have been mentioned above, a set of improved stepped eco-filter (EF) process based on the $\mathrm{CW}$ and the $\mathrm{VF}$ was designed above the ground to treat the GW from a farm household in mountainous rural regions. The aim of this study was to investigate the operating parameters for the maximum removal rate of an on-site EF process constructed according to the local conditions while treating the GW from a single farm house, as well as its general performance during the operating period of an entire year.

\section{Materials and methods}

\section{Pilot plant setup}

The pilot facility was built in a typical farm house located in the Three Gorges Reservoir region of China, which were composed of influent collecting pipes, one settling tank, and two ecological tanks. These units were connected sequentially and positioned from high to low elevation to allow for gravity driven fluid flow. This way, the facility could operate without energy consumption (Fig. 1a). All the tanks were handled by PVC frame, which measures $80 \mathrm{~cm}$ long, $60 \mathrm{~cm}$ wide and $65 \mathrm{~cm}$ high, respectively. The water distributors were made of a row of PVC pipes that each was drilled with six small holes ( $2 \mathrm{~mm}$ diameter). These distributors were placed $20-30 \mathrm{~cm}$ above the surface soil of the tanks. Cock taps were inserted near the bottom of the tanks for the sampling of the effluent.

From the bottom to the top, the ecological tanks were designed as catchments layer $(0-10 \mathrm{~cm})$, board supporting layer $(10-12 \mathrm{~cm})$, slag layer $(12-22 \mathrm{~cm})$, gravel layer $(22-32 \mathrm{~cm})$, soil layer $(32-60 \mathrm{~cm})$ and vegetation layer. The slag and gravel were solid waste collected in the village, the physical characteristics of the slag and gravel was shown in the Table 1. The soils were collected from the mountains near the farm house, which was evenly mixed with sands by volume ratio of 3:1. Earthworms were collected from the vegetable garden nearby and were put into the soil layer with the density of 40 worms per square meter of soil. In the vegetation layer, ornamental and evergreen plants were planted using Ophiopogon japonicus and Rhododendron simsii Planch; a good long-term stability of landscape of the EF was formed as these plants live a normal life all year around (Fig. 1b).

\section{Experimental design}

In regular sequence, this experiment was divided into three stages including the set-up phase, the HLR optimization test and the continuous operation test. The set-up phase was designed for the acclimatization of the microorganism, earthworms and plants. Influent GW was collected by PVC pipes from the typical single household. Operating period of the process was set from 9:00 to 15:00 everyday, and this was automatically controlled by a relay and a peristaltic pump; so the wet-to-dry time ratio was maintained at $1: 3$. The duration of the set-up phase was 60 days, and the influent flow rate was designed as slow as $65 \mathrm{~mL} / \mathrm{min}$, or a HLR of $0.05 \mathrm{~m}^{3} /\left(\mathrm{m}^{2}\right.$ day $)$. The period of the HLR optimization test was planned as 100 days, the HLR was designed four stages as $0.05 \mathrm{~m}^{3} /\left(\mathrm{m}^{2}\right.$ day) (stage 1$), 0.1 \mathrm{~m}^{3} /$ ( $\mathrm{m}^{2}$ day) (stage 2$), 0.2 \mathrm{~m}^{3} /\left(\mathrm{m}^{2}\right.$ day) (stage 3$), 0.4 \mathrm{~m}^{3} /$ $\left(\mathrm{m}^{2}\right.$ day) (stage 4$)$ with the operating time of 20, 20, 20, 30 days, respectively. To investigate the long-term performance of the process under the HLR of $0.2 \mathrm{~m}^{3} /$ $\left(\mathrm{m}^{2}\right.$ day), the continuous operation test was operated continuously over an entire year. The adjustable valve was used to maintain the HLR condition instead of using the peristaltic pump; thus, the GW was flowing by gravity and the process operating without energy consumption in this period. 


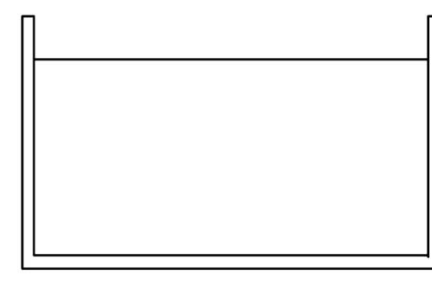

collecting sump
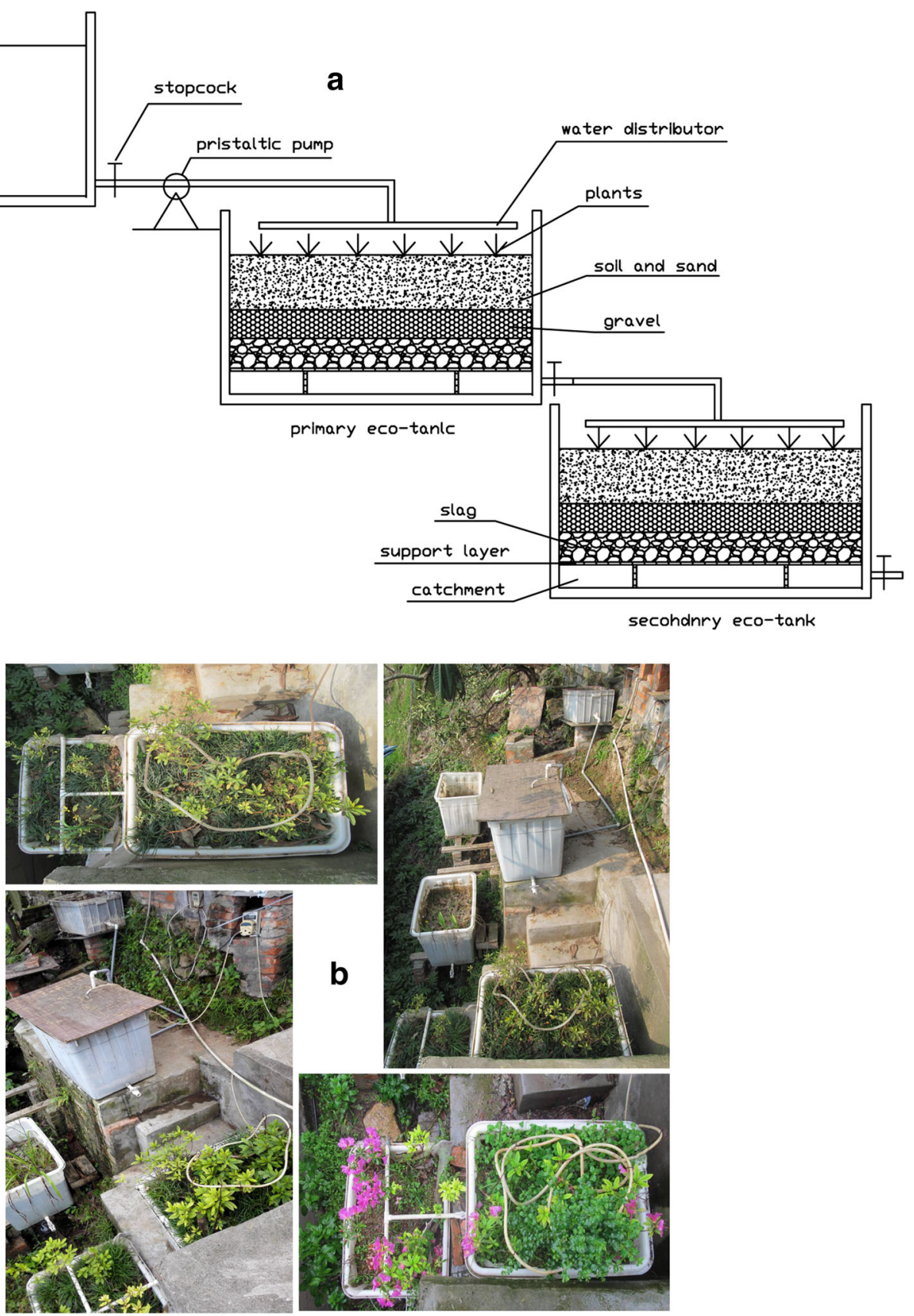

b
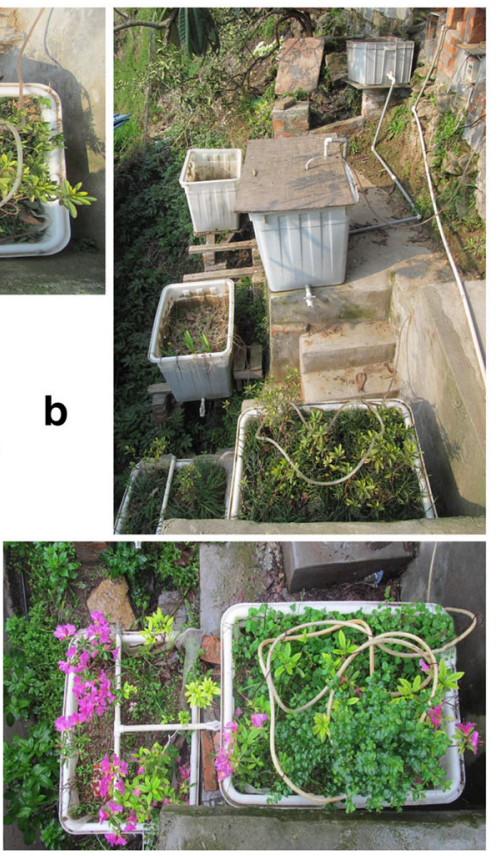

Fig. 1 a Schematic diagram of EF; b photographs of the EF in different seasons

Table 1 Characteristics of the block fillings in the EF

\begin{tabular}{lllllll}
\hline Fillings & $\begin{array}{l}\text { Particle } \\
\text { size }(\mathrm{cm})\end{array}$ & $\begin{array}{l}\text { Apparent } \\
\text { density }\left(\mathrm{g} / \mathrm{cm}^{3}\right)\end{array}$ & $\begin{array}{l}\text { Actual density } \\
\left(\mathrm{g} / \mathrm{cm}^{3}\right)\end{array}$ & $\begin{array}{l}\text { Particle porosity } \\
(\%)\end{array}$ & $\begin{array}{l}\text { Packing } \\
\text { density }\left(\mathrm{g} / \mathrm{cm}^{3}\right)\end{array}$ & $\begin{array}{l}\text { Packing } \\
\text { porosity }(\%)\end{array}$ \\
\hline Gravel & $1-2$ & 2.63 & 2.66 & 1.13 & 1.40 & 38.7 \\
Slag & $2-4$ & 2.10 & 2.71 & 22.5 & 0.692 & 74.5 \\
\hline
\end{tabular}




\section{Sampling and analytical methods}

Influent and effluent of the system were sampled and monitored continuously during the experiment period. The $\mathrm{COD}, \mathrm{NH}_{4}{ }^{+}-\mathrm{N}, \mathrm{TP}$, and the LAS were measured according to the Standard Methods for the examination of water and wastewater (APHA 1998). The removal efficiency was calculated as the percent removal for each parameter: $R=\left(1-C_{\mathrm{e}} / C_{\mathrm{i}}\right) \times 100 \%$, where the $C_{\mathrm{e}}$ and $C_{\mathrm{i}}$ are the influent and effluent concentrations in $\mathrm{mg} / \mathrm{L}$, respectively. The $\mathrm{pH}$ and temperature were determined in situ by the portable pH meter (OHAUS STARTER 300, USA), and the moisture content in the soil was measured on-site by portable soil moisture tester (TRIME-P, Germany).

\section{Statistical analysis}

Analysis of the experiments data was performed by the software of SPSS 16.0 and Surfer 8.0, and the $p$ value less
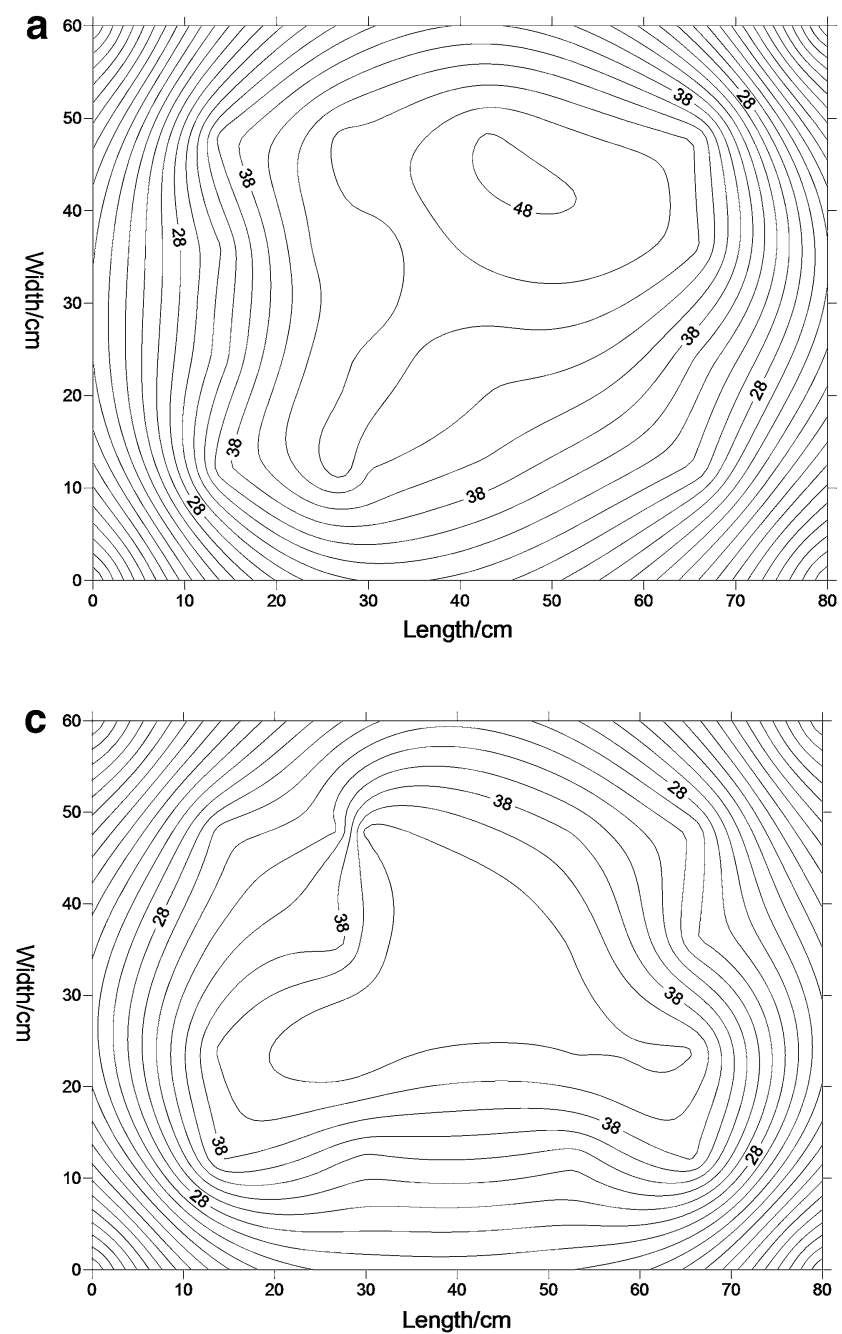

than $0.05(p<0.05)$ was interpreted to declare the differences of significant level. The one-way analysis of variance (ANOVA) and the least significant difference (LSD) was performed to analyze the differences between average values of the effluent for each physicochemical parameter.

\section{Results and discussion}

\section{Effect of the HLR on the removal rates of the process}

The set-up phase lasted about 60 days, which was mainly aimed to observe the adaptation of the earthworms and plants in the ecological tank. The effect of the GW distribution was tested in the wet and dry period separately, 20 sampling points for moisture measurement were set in the horizontal plane at the depth of $15 \mathrm{~cm}$ under the soil surface in each tank. The test results showed that the moisture
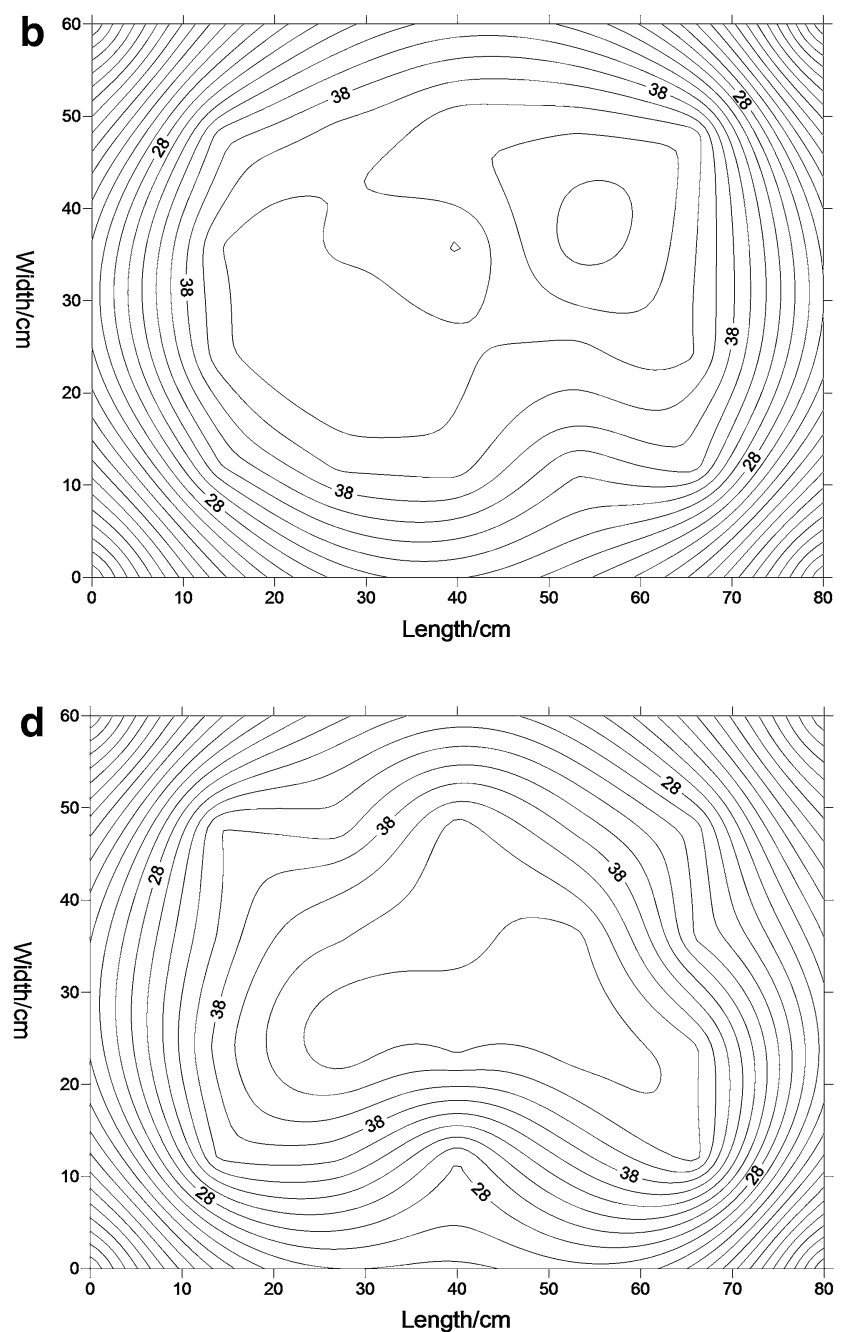

Fig. 2 Contour of the soil moisture content in the two tanks: a the first tank in the wet period; $\mathbf{b}$ the first tank in the dry period; $\mathbf{c}$ the second tank in the wet period; $\mathbf{d}$ the second tank in the dry period. The results are represented in percentage (\%) 

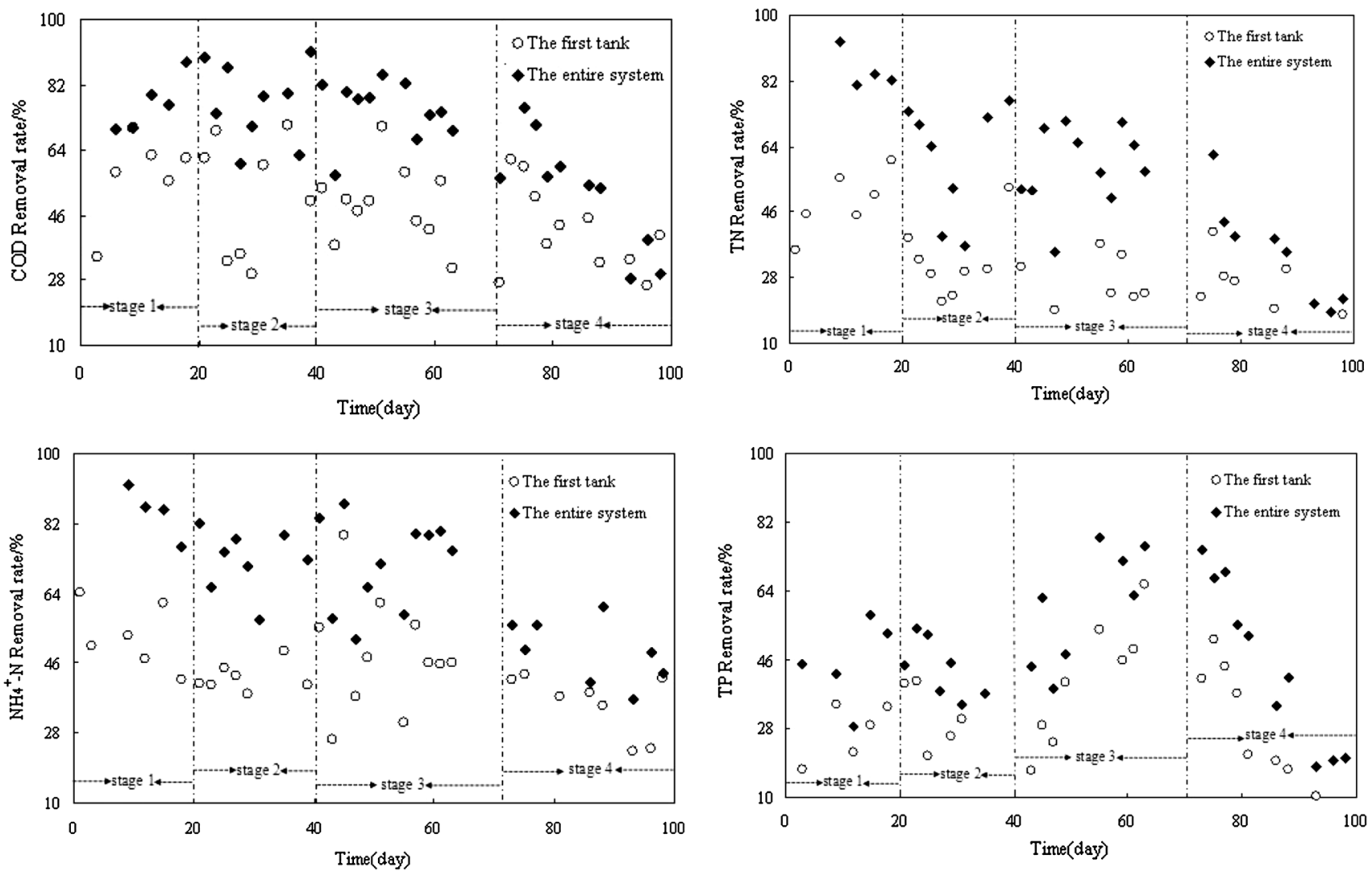

Fig. 3 Effect of HLR on the removal efficiency of the process

was evenly distributed in the soil layer of the two ecology tanks (Fig. 2).

In the 30th day of this period, the plants thrived well and earthworms could be found alive after scooping up handfuls of soil. Then, the COD, TN, $\mathrm{NH}_{4}{ }^{+}-\mathrm{N}, \mathrm{TP}$ of the influent and effluent of the first ecological tank was monitored for a month. The average removal efficiency of COD, TN, $\mathrm{NH}_{4}{ }^{+}-\mathrm{N}$, TP during the set-up phase was 63,64 , 77 and 59\%, respectively. All the indexes of the influent gradually decreased, but the removal rates of COD, TN, $\mathrm{NH}_{4}{ }^{+}-\mathrm{N}$ showed comparatively stable except for TP, this may attributed to the rather low content of TP in the influent. Moreover, the frequent rains in that period caused the decline of all the indexes of the influent.

Thus, covers and GW collecting pipes were designed to eliminate the effect of the rainfall after the start-up experiment. The removal rate changes of COD, $\mathrm{NH}_{4}{ }^{-}-\mathrm{N}, \mathrm{TP}$, turbidity during the HLR optimization test are presented in Fig. 3, and the HLR was designed four stages from stage 1 to stage 4 with the value was $0.05 \mathrm{~m}^{3} /\left(\mathrm{m}^{2}\right.$ day $), 0.1 \mathrm{~m}^{3} /$ ( $\mathrm{m}^{2}$ day $), 0.2 \mathrm{~m}^{3} /\left(\mathrm{m}^{2}\right.$ day $)$, and $0.4 \mathrm{~m}^{3} /\left(\mathrm{m}^{2}\right.$ day $)$, respectively. From the change regulations of the removal rates in Fig. 3, it can be concluded that the optimal HLR of the process will located in the range of $0.2-0.4 \mathrm{~m}^{3} /\left(\mathrm{m}^{2}\right.$ day $)$. Compare to the similar processes, the optimal HLR of this process was a little higher as the HLR reported in the related studies were $0.06-0.25 \mathrm{~m}^{3} /\left(\mathrm{m}^{2}\right.$ day) (Luederitz et al. 2001; Kantawanichkul et al. 2013). It may attribute to the reason that the fillings mode and the operation condition of this process were different from the VFCW, although it was more similar to the VFCW compared to the other ecological process.

The removal rates of COD, $\mathrm{TN}, \mathrm{NH}_{4}{ }^{+}-\mathrm{N}$, and TP changed differently with the increasing of HLR from 0.05 to $0.4 \mathrm{~m}^{3} /$ $\left(\mathrm{m}^{2}\right.$ day), as was shown in the Fig. 3. The removal rate of COD, $\mathrm{TN}, \mathrm{NH}_{4}{ }^{+}-\mathrm{N}$, and TP were all gradually declining with the increasing of HLR, while the further decline was observed under the HLR of $0.4 \mathrm{~m}^{3} /\left(\mathrm{m}^{2}\right.$ day $)$. The hydraulic retention time (HRT) was shorter when the HLR was upregulated; therefore, the interception and the absorption functions of the EF were degraded at the same time. With the increasing of the HLR, the removal rates of the most indexes represented the trends of reduction; this is also consistent with the most of the previous works.

Unlike the other related works, the removal rate of TP increased as the HLR elevated from 0.1 to $0.2 \mathrm{~m}^{3} /\left(\mathrm{m}^{2}\right.$ day) before decreasing during the HLR increased from 0.2 to $0.4 \mathrm{~m}^{3} /\left(\mathrm{m}^{2}\right.$ day $)$. The removal of the TP in the EF system mainly due to the absorption and precipitation of phosphorus on the packing, and the maximum adsorptive capacity could be enhanced with the increment of the TP 
content in a certain range (Cheol et al. 2005). In this study, the concentration of TP in the influent was much lower compared to other reports, which is the reason for the low removal rate. In similar, it explains why the TP removal rate was increasing as the HLR was up-regulated from 0.1 to $0.2 \mathrm{~m}^{3} /\left(\mathrm{m}^{2}\right.$ day) (Fig. 3 ).

\section{Treatment performance of the process in the continuous operation test}

Based on the conclusions of the HLR optimization tests, the process was operating continuously under the HLR of $0.2 \mathrm{~m}^{3} /\left(\mathrm{m}^{2}\right.$ day $)$ over one entire year. The COD, $\mathrm{NH}_{4}{ }^{+}-\mathrm{N}$, TP, turbidity and LAS of the influent and the effluent Water from the influent, effluent (including the first tank and the entire system) were sampled and monitored 3-4 times every month during the year. The average values and the removal rates was calculated and listed in Table 2.

Compared to the general characteristics of GW data collected by previous studies (Donner et al. 2010; Ghaitidak and Yadav 2013), the means of COD, TP, turbidity and $\mathrm{pH}$ in this study were within the same rang. However, the data from this examine were all in a comparatively lower range. This is because the GW was mainly from the bathroom and the wash basin in this experiment, a much lower percentage of sources from laundry and kitchen considerably reduces the organic load and total solid content of the GW. Furthermore, the characteristics of COD, $\mathrm{TP}$, turbidity in GW from this farmer household were more consistent with the water quality from bathroom (Ghaitidak and Yadav 2013; Assayed et al. 2015). These results support the conclusion that the characteristics of greywater are mainly determined by the source, lifestyle, and daily activities of the household (Eriksson et al. 2009). Variations of the LAS in GW had rarely been elucidated in the related research, and the data of which from our study were in the range but in a comparably high level than that from the other investigations. It may attribute to the fact that the $\mathrm{GW}$ in this experiment are mainly composed of washing dishes and laundry water from farmer household, which contains a large amounts of LAS because of the excessively use of detergent and soap by the family members.

In this study, concentration of the $\mathrm{TN}, \mathrm{NH}_{4}{ }^{+}-\mathrm{N}$ and TP in the effluent satisfied the need of "Urban Sewage Treatment Plant Pollutant Discharge Standard" (GB18918-2002) primary standard Class A, and the content of the COD met the secondary standard. The GW output of a household within a day varies considerably in different seasons through out a year. On the whole, the average amount of the greywater generated from the household was in the range of $0.1-0.4 \mathrm{~m}^{3} /$ day in the rural area. Initially, we did not intend to treat all the greywater discharged from the peasant household in this experiment. Our purpose is to investigate a range value of the optimal HLR of this process by treating part of the discharged greywater. The results showed that, the optimal HLR of the process was ought to be in the range of $0.2-0.4 \mathrm{~m}^{3} /\left(\mathrm{m}^{2}\right.$ day $)$. Based on this result, it can be concluded that when we set out to treat all the greywater from the peasant household in future practical application, we only need to increase the surface area of our EF tank to some value of $1-2 \mathrm{~m}^{2}$ based on the data of this experiment.

In addition, the removal efficiency of the COD, TN, $\mathrm{NH}_{4}{ }^{+}-\mathrm{N}$, TP, turbidity, LAS averaged to be $67,55,64,43$, $68,71 \%$, respectively (Table 2). The removal rates of COD and TP in this examine was obviously lower than the most related facility (Wang et al. 2011; Zhao et al. 2012), it is due to the fact that only two EF tanks (the first tank and the second tank) were concatenated in this study but three tanks were designed in their experiment, added with the big fluctuations of the influent character during the entire year. As can be deduced from our data, the removal efficiency of COD and LAS could be enhanced to satisfaction if the third EF tanks or recycling measures are in further connected to the process. The removal rate of LAS was averaged as $71 \%$, which mainly attribute to the living plants and the depth of the packing (Huang et al. 2004; Kadewa et al. 2010). Despite the removal rate of LAS was not so good by the this EF process, the content of LAS in the influent was

Table 2 The concentration and the removal efficiency of the process in the continuous test during an entire year

\begin{tabular}{|c|c|c|c|c|c|c|}
\hline \multirow[t]{2}{*}{ Items } & \multirow[t]{2}{*}{ Sample size $(n)$} & \multirow[t]{2}{*}{ Influent $^{\mathrm{a}}$} & \multicolumn{2}{|l|}{ Effluent $^{\mathrm{a}}$} & \multicolumn{2}{|l|}{ Removal rate $(\%)^{\mathrm{a}}$} \\
\hline & & & The first tank & The entire system & The first tank $(\%)$ & The entire system (\%) \\
\hline COD (mg/L) & 58 & $302 \pm 110$ & $151 \pm 82.7$ & $98.5 \pm 49.4$ & $50.6 \pm 12.7$ & $67.2 \pm 15.3$ \\
\hline $\mathrm{TN}(\mathrm{mg} / \mathrm{L})$ & 48 & $12.2 \pm 5.59$ & $7.36 \pm 2.35$ & $5.67 \pm 2.37$ & $35.1 \pm 17.5$ & $54.5 \pm 12.8$ \\
\hline $\mathrm{NH}_{4}{ }^{+}-\mathrm{N}(\mathrm{mg} / \mathrm{L})$ & 58 & $7.04 \pm 2.25$ & $3.59 \pm 2.51$ & $2.59 \pm 2.00$ & $50.4 \pm 21.1$ & $63.5 \pm 16.6$ \\
\hline $\mathrm{TP}(\mathrm{mg} / \mathrm{L})$ & 58 & $0.922 \pm 0.319$ & $0.551 \pm 0.139$ & $0.480 \pm 0.115$ & $35.2 \pm 16.2$ & $43.3 \pm 12.8$ \\
\hline Turbidity (NTU) & 53 & $106 \pm 49.1$ & $62.9 \pm 32.9$ & $34.5 \pm 20.3$ & $40.5 \pm 19.0$ & $67.6 \pm 14.4$ \\
\hline LAS $(\mathrm{mg} / \mathrm{L})$ & 32 & $55.3 \pm 15.7$ & $31.8 \pm 6.79$ & $15.82 \pm 4.90$ & $42.6 \pm 3.52$ & $71.4 \pm 5.24$ \\
\hline $\mathrm{pH}$ & 58 & $7.58 \pm 0.261$ & $7.79 \pm 0.204$ & $7.86 \pm 0.198$ & - & - \\
\hline
\end{tabular}

${ }^{a}$ Mean concentration \pm standard deviation of the physicochemical parameters 
near to the discharge standard, and predictably the content of LAS in the influent will lower than the discharge standard if a third similar tank was added and connected to this process.

Technologies including physical, chemical, and biological systems were already applied for GW treatment. Up to date, the technologies of membrane filtration, such as membrane bioreactor (MBR) or direct UF/MF filtration, are more frequently used for the single households $\mathrm{GW}$ treatment by the water-treatment companies, however, the investment of MBR for single household is still too high when the payback time is almost 15 years (Jabornig and Favero 2013; Jabornig 2014). Householders' poll showed that about $23 \%$ respondents were reluctant to pay any money on the sewage treatment facility, which means that the cost of the facility must be extremely low so that the rural villages could accept it (Wu et al. 2011). In this study, the sum construction cost including the experimental expense of the process is very low as 160 US dollars (Table 3). Since a large proportion of the cost is from the frame structure and the installation, a big reduction of the sum cost can be acquired by directing the farmer to build and install the frame structure using cheap raw material such as concrete.

Clogging is the biggest problem to the most bio-ecological processes such as the Constructed Wetland and the Filtration. However, clogging was not experienced in this study, probably because the trapped solids in the soil were preyed by the earthworms or degraded by the microorganisms promptly. In addition, the packing porosity in the gravel layer and the slag layer are both in a comparably high level (Table 1), which may have reduced the chance of clogging happening. The EF is easy maintaining because of the following reasons: (1) it was designed according to the terrain conditions of hilly areas, which run by gravity and do not need additional equipment such as pumps; (2) the process has showed stable treatment effect during an entire year and no clogging was observed during the period, the only required maintenance was pruning the plants and pulling the weeds in the tanks. From what have been

Table 3 Construction and experimental cost of the household ecofilter

\begin{tabular}{ll}
\hline Items & Cost (US dollars) \\
\hline Precast frame structure & 30 \\
Gravel, slag and soil & $0-5$ \\
Installation & 100 \\
Pipes and joints & 20 \\
Plants & $0-5$ \\
Excavation & 0 \\
Sum & 160 \\
\hline
\end{tabular}

discussed above, it could be concluded that with the advantage of lower cost and easier maintenance, the EF technology with its improvements for GW treatment has high applicability in the rural areas of developing country.

\section{Impacts of the environment temperature on the process}

The effect of the air temperature on the performance of the EF was examined based on the comparison of the data from the summer and winter in a year, with the temperature 21-30 ${ }^{\circ} \mathrm{C}$ in summer and $5-12{ }^{\circ} \mathrm{C}$ in winter. In the summer, the system removal rate of COD, TN, TP, LAS was 77, 65, $45,76 \%$ and the corresponding value in the winter was 60 , $48,41,68 \%$, respectively. All the removal rates from summer were observed higher than those from winter, and this was in agreement with the previous study (Zhao et al. 2012). In contrast, the removal rate of TP in winter was in close proximity to that in summer, and the significant different $(p<0.05)$ of removal rate between the summer and winter was only detected in COD (Fig. 4). Probably, the very low concentration of TP in the influent has limited the increase of the removal rate to phosphorous in summer. Due to a similar reason, the significant difference of removal rates between summer and winter could only be detected in the index of COD, for the COD content in the influent was moderate according to the GW quality reported previously.

While treating the GW, the mechanisms of the EF included the filtering absorption in the layer of soil and packing, and the bio-chemical retention of the plant root and microorganism. Moreover, the existing of the earthworm was proved effectively in enhancing the physical and the bio-chemical reactions by Edwards and Fletcher (1988). Thus, it explains that the higher temperature in summer enhances the life activity of the plant, microorganism and earthworm as well as the synergistic effect among them; this was the reason for the higher removal efficiency. It is worth noting that the process still performed well in the winter, this may be attributed to the living of the Ophiopogon japonicus and Rhododendron simsii Planch in the soil. Furthermore, the covering of the Ophiopogon japonicus above the tanks could offer a heat preservation function, which enabled the continuing biological activity inside the soil.

\section{Conclusions}

A set of gravity flow stepped eco-filter process was conducted to treat GW generated from a single farm house over an entire year, and the impacts of HLR and environment temperature were investigated in this experiment. The average values of the most indexes in the influent $\mathrm{GW}$ were 

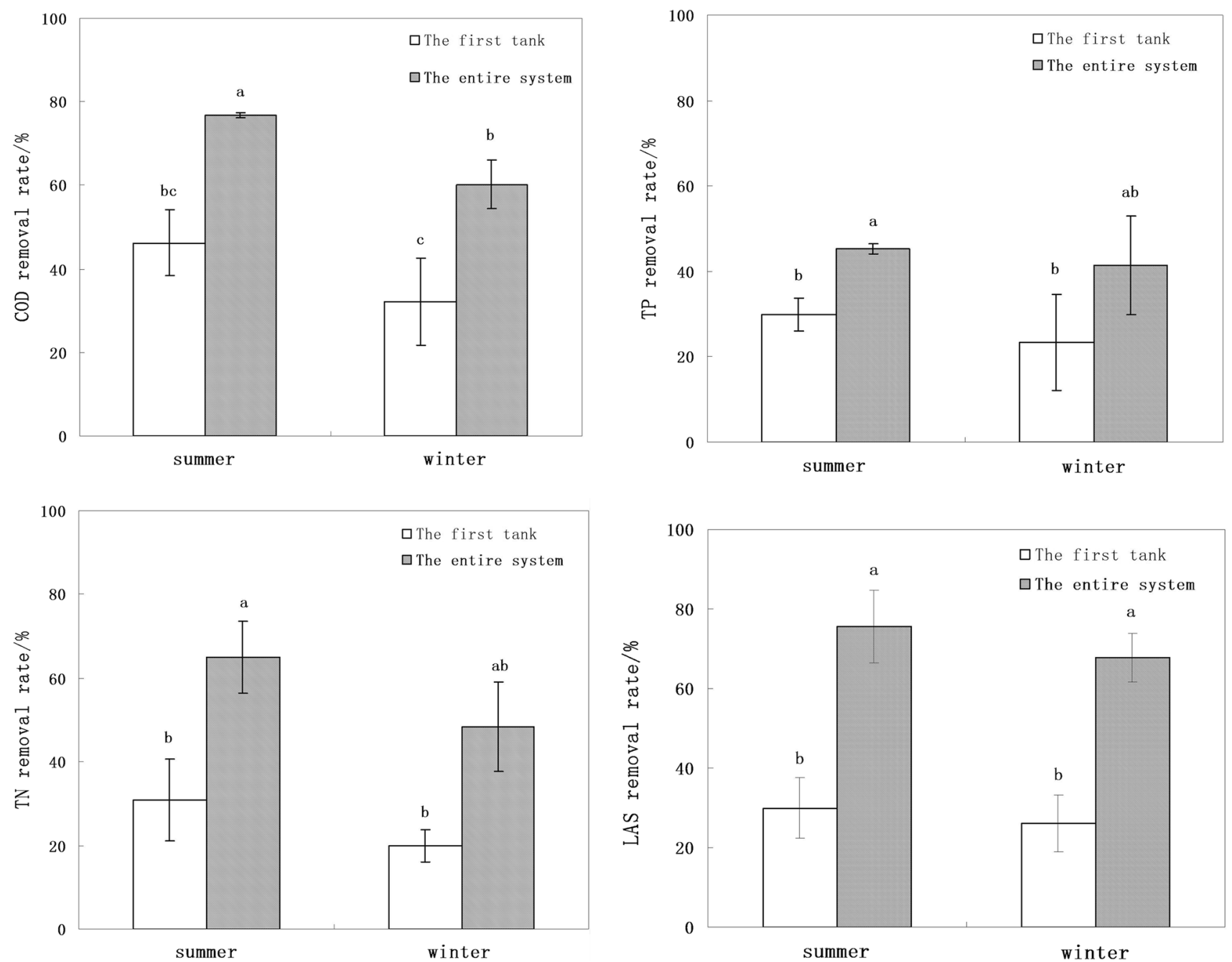

Fig. 4 Effect of seasonal temperature change on the removal rates of the process

relatively low but in the range of the previous study, except for that of the LAS. The removal rates changed differently with the increase of HLR, and the optimal HLR is in the range of $0.2-0.4 \mathrm{~m}^{3} /\left(\mathrm{m}^{2}\right.$ day $)$ for this facility. The facility was operating all year round; the average removal rate of the COD, TN, $\mathrm{NH}_{4}{ }^{+}-\mathrm{N}, \mathrm{TP}$, turbidity and LAS was 67,55 , 64, 43, 68 and $71 \%$, respectively.

The average removal rates in summer were all higher than those in winter. However, the process still performed well in winter. The difference of the COD removal rate was significant $(p<0.05)$ between the summer and winter and, however, that of TP was hardly observed. Clogging has never occurred in the process while it was operating over one entire year. Overall, the facility demonstrated high performance, low cost and easy maintaining.

Acknowledgements This research was financially supported by the National Natural Science Fundation of China (41401586, 21407091). Thank Prof Zaiyi Liao (Hubei Chutian Scholar) for language help and proof reading the article, also thank Guangcai Hu, Xifeng Chen for assistance with sampling collection and analysis. The authors would like to thank the anonymous reviewers for useful suggestions, too.

Open Access This article is distributed under the terms of the Creative Commons Attribution 4.0 International License (http:// creativecommons.org/licenses/by/4.0/), which permits unrestricted use, distribution, and reproduction in any medium, provided you give appropriate credit to the original author(s) and the source, provide a link to the Creative Commons license, and indicate if changes were made.

\section{References}

Adugna AT, Andrianisa HA, Konate Y et al (2014) Greywater treatment by vermifiltration for sub-Saharan urban poor. J Water Sanit Hyg Dev 4:625-632

APHA (1998) Standard methods for the examination of water and wastewater, 20th edn. American Public Health Association, Washington

Assayed A, Chenoweth J, Pedley S (2015) Assessing the efficiency of an innovative method for on-site greywater treatment: drawer 
compacted sand filter-a case study in Jordan. Ecol Eng 81:525-533

Cheol SD, Sik CJ, Jae LH, Soo HJ (2005) Phosphorous retention capacity of filter media for estimating the longevity of constructed wetland. Water Res 39:2445-2457

Donner E, Eriksson E, Revitt DM et al (2010) Presence and fate of priority substances in domestic greywater treatment and reuse systems. Sci Total Environ 408:2444-2451

Edwards CA, Fletcher KE (1988) Interactions between earthworms and microorganisms in organic-matter breakdown. Agric Ecosyst Environ 24:235-247

Edwin GA, Gopalsamy P, Muthu N (2014) Characterization of domestic gray water from point source to determine the potential for urban residential reuse: a short review. Appl Water Sci 4:39-49

Eriksson E, Andersen HR, Madsen TS et al (2009) Greywater pollution variability and loadings. Ecol Eng 35:661-669

Ghaitidak DM, Yadav KD (2013) Characteristics and treatment of greywater-a review. Environ Sci Pollut Res 20:2795-2809

Gross A, Shmueli O, Ronen Z et al (2007) Recycled vertical flow constructed wetland (RVFCW) - a novel method of recycling greywater for irrigation in small communities and households. Chemosphere 66:916-923

Halalsheh M, Dalahmeh S, Sayed M et al (2008) Grey water characteristics and treatment options for rural areas in Jordan. Bioresour Technol 99:6635-6641

Huang YM, Ana L, Damià B et al (2004) Factors affecting linear alkylbenzene sulfonates removal in subsurface flow constructed wetlands. Environ Sci Technol 38:2657-2663

Huelgas A, Funamizu N (2009) Flat-plate submerged membrane bioreactor for the treatment of higher-load graywater. Desalination 250:162-166

Jabornig S (2014) Overview and feasibility of advanced grey water treatment systems for single households. Urban Water J $11: 361-369$
Jabornig S, Favero E (2013) Single household greywater treatment with a moving bed biofilm membrane reactor (MBBMR). J Membr Sci 446:277-285

Kadewa WW, Le Corre K, Pidou M et al (2010) Comparison of grey water treatment performance by a cascading sand filter and a constructed wetland. Water Sci Technol 62:1471-1478

Kantawanichkul S, Sattayapanich S, Dien FV (2013) Treatment of domestic wastewater by vertical flow constructed wetland planted with umbrella sedge and Vetiver grass. Water Sci Technol 68:1345-1351

Li FY, Wichmann K, Otterpohl R (2009) Review of the technological approaches for grey water treatment and reuses. Sci Total Environ 407:3439-3449

Luederitz V, Eckert E, Lange-Weber M et al (2001) Nutrient removal efficiency and resource economics of vertical flow and horizontal flow constructed wetlands. Ecol Eng 18:157-171

Marc P, Lisa A, Tom S et al (2007) Chemical solutions for greywater recycling. Chemosphere 71:147-155

Ushijima K, Ito K, Ito R et al (2013) Greywater treatment by slanted soil system. Ecol Eng 50:62-68

Wang S, Yang J, Lou SJ (2010) Wastewater treatment performance of a vermifilter enhancement by a converter slag-coal cinder filter. Ecol Eng 36:489-494

Wang LM, Zheng Z, Luo XZ et al (2011) Performance and mechanisms of a microbial-earthworm ecofilter for removing organic matter and nitrogen from synthetic domestic wastewater. J Hazard Mater 195:245-253

Wu SB, Austin D, Liu L et al (2011) Performance of integrated household constructed wetland for domestic wastewater treatment in rural areas. Ecol Eng 37:948-954

Zhao YJ, Cheng Y, Li YL et al (2012) Effect of C/N ratios on the performance of earthworm eco-filter for treatment of synthetics domestic sewage. Environ Sci Pollut Res 19:4049-4059 